\title{
استخدام طريقة مقلوب المسافة الموزونة IDW لإنتاج خرائط لبعض خواص التربة في محطة الابحاث الزراعية جامعة طرابلس
}

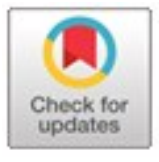

\author{
ماجدة بشير البشتي" أبوعبدالله سعد الثريف وإيهاب محمد الصقر \\ قسم التربة والمباه، كلية الزراعة، جامعة طرابلس، طرابلس -ليبيا
}

\section{تاريخ الاستلام: 04 مايو 2019 / تاريخ القبول: 30 ديسمبر 2019 https://doi.org/10.54172/mjsc.v34i4.207:Doi}

المستخلص: هدفت الدراسـة لتحديد الاختلافات المكانية لبعض الخواص الفيزيائية والكيميائية لعينات تربـة محطات أبحاث كلية الزراعة/ جامعة طرابلس في شهر أبريل 2013، واستخدمت النتائج لإنتاج خرائط مكانية لمعرفة التوزيع المكاني لكل من الخواص

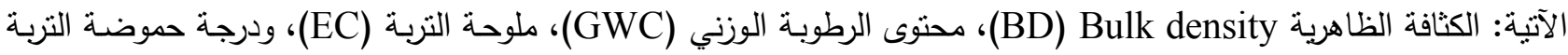
(pH) مساحتها 13200 م² تقريبا قُسمت إلى شبكة بأبعاد 12 م 11 11م لنتتج 100 وحدة مساحية وأختبرت 36 وحدة حددت إحداثياتها بواسطة جهاز GPS المحمول لتجميع العينات منها. أجريت تحاليل لكل من BD و GWC من الأعماق 0-10 سم، 10-20 سم

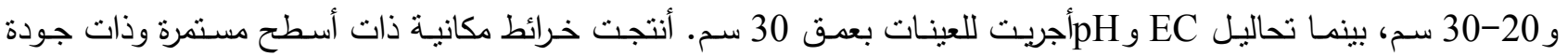
اختلفت من خاصية لأخرى حسب قيم الجذر التربيعي لمتوسط الخطأ RMSE)Root Mean Square Error). Rن من النتائج

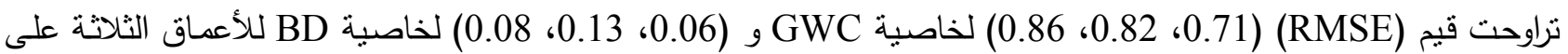
التوالي. بينمـا كانت قيم RMSE (0.15، 0.84) لخاصيتي pH و EC على التوالي. أظهرت قيم RMSE المنخفضـة لخرائط عند العمق الأول والثالث وكذلك خريطة pH مؤشر جودة أعلى للخرائط. بينما بينت قيم (RMSE) المرتفعة نوعا ما بأن الخرائط المنتجة لكل من خاصيتي EC و GWC كانت أقل جودة. خلصت هذه الدراسة إلى إمكانية إنتاج خرائط مكانية متفاوتة الجودة لبعض خواص التربـة داخل الحقل باستخدام IDW. وبالتالي يمكن استخدام هذه الخرائط للتتبؤ بخاصيتي BD و الحقل، بينما يصعب استخدامها للتتبؤ بخاصيتي EC و GWC، ولهذا ينصح باستمرار البحث في إمكانية إنتاج خرائط ذات جودة عالية بطرق أخرى لهاتين الخاصيتين مع مراعاة زيادة عدد العينات.

الكلمات المفتاحية: مقلوب المسافة الوزنية، الكثافة الظاهرية، المحتوى الرطوبي الحجمي، ملوحة التربة، درجة حموضة التربة.

هنا كان من الضـروري استعمال طرق تحديد هذه الخـواص

المقدمة

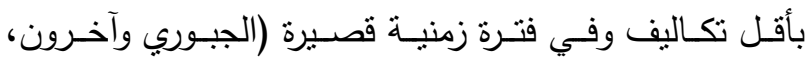
تعـد التربـة أحد أهـم مصسادر الثروات الطبيعيـة في العـالم، .$(2015$ وتتباين الترب في خصائصها الفيزيائية والكيميائية مثل القوام

في السنوات الأخيرة ألقت علوم التربـة الضـوء على استخدام والكثافة الظاهريـة والحقبقية والمسامية بالإضـافة لارجة تفاعل الإحصـاء المكاني الذي يعطينا الدقة المكانيـة لصفات التربـة التربة وملوحتها من مكان إلى آخر داخل الحقل الواحد؛ حيث

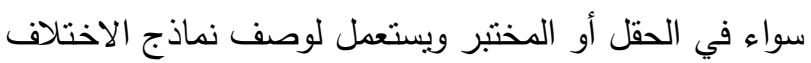

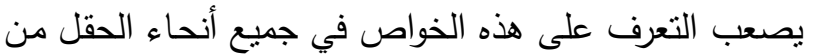

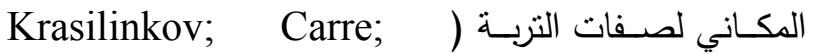
خلال تحليل عينات التربة وذلك لارتفاع التكاليف والوقت، من لهن 
التحليـلـ الإحصــائي للبيانــات المكانيــة و تطــور تقنيــات الاستشعار عن بعد) (Remote Sensing) 1997)، وأنظمة تحديد المواقع العالمية و على رأسـها نظام (GPS) Hand Held Global Positioning System كمصدر للبيانـات الحقليـة سـاهم مسـاهمة كبيـرة في انتشـار

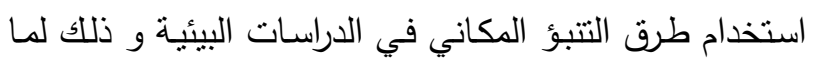

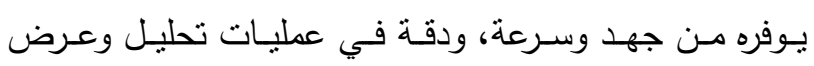
البيانات المكانية(Burrough, 1986).

هناك العديد من طرق التتبؤ المكاني المتوفرة مثنل طريقة


(Spatial اللتين أساسهما عملية التوليد المكاني (Kriging) والتي تعتبر هي العملية الأساسية في طرق Interpolation)

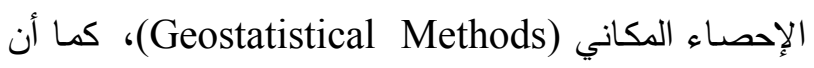

هذه الطـرق تسـتعل افتراضـية أن هنـاك علاقـات مكانيـة للعينـات المقيسـة لأي خاصـية (Spatial Correlation) داخل الحقل (Cay and Uyan, 2010). وتعرف عملية (Interpolation) في مواقع جغرافية غير مقيسة مستخدماً بيانات جغرافية مقاسـا

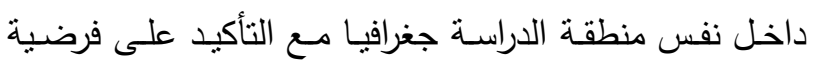
وجود علاقة مكانية للخاصية المقيسة داخل الحقل، حيث تنم هذه العملية بواسطة معادلات وحسـابات رياضية وإحصـائية، بعد ذللك يتم تمثيل وعرض هذه البيانات في سطوح مستمرة (Continues Surfaces)

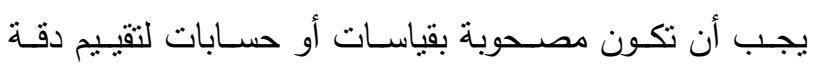
عمليات الإنشاء (Interpolation)، فنتستعل المقاييس مثل: متوسط الخطأ Mean Error ) ، منوسط الخطاء التربيعي MSE) Mean Square Error)، والجذر التربيعي Root Mean Square Error لمتوسط مربع الخطا (RMSE) بين القيم المقيسة والقيم (R2) ومعامل التحديد (Mardia and Jupp, المسنتبطة كمؤشر لدقة هذه العمليات ومعلمل .2000; Chile`s and Delfiner, 1999)
Montanarella, 2008) التربـة مهمة في فهم صفات التربـة ودليل مهم لأخذ العينات الخاصـة بالتحاليل المختلفة، كذلك معرفة الاختلاف الموجود في التربـة يمكن الاستفادة منهـه في تطوير النموذج المستخدم

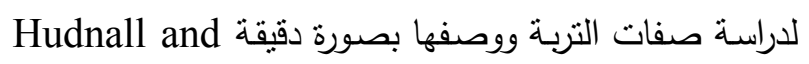
Bekele, 2006). ( إن الهدف الأساسي من دراسـة التغاير أو الاختلاف المكاني

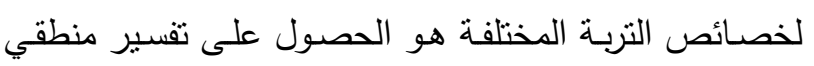
لهذه التغايرات، وكذلك التتبؤ بقيم خواص التربة المختلفة عند

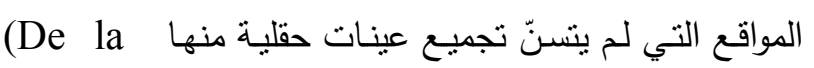
. , وآخرونRosa, 1979; Burrough, 1989; White 1989; Talkkari المعلومات الجغرافية طرائق عدة في دراسة التغايرات المكانية

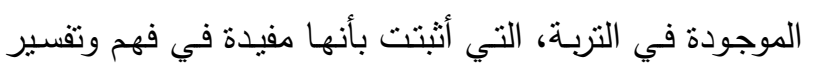

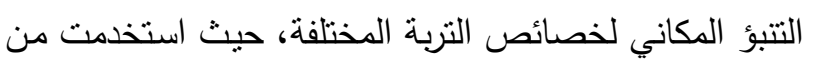
قبل العديد من الباحثين في مجال علم التربة لدراسة التغايرات

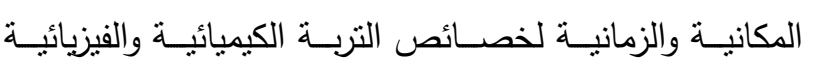
, 1993; Usowicz, وآخرون Burrough, 1993; Fahad) . 2004, Corwin and Lesch, 2005; Santra 2008, Camachu

(2009

تعتبر طرق الإحصاء المكاني (Geostatistic) المختلفة من الطرق المستخدمة في تحليل، تمنيل وعرض البيانات المكانية

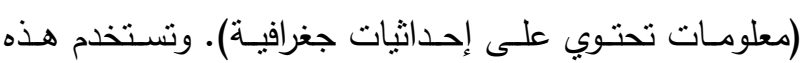
الطرق على نطاق واسع في الدراسات البيئية بصفة عامـة وفي

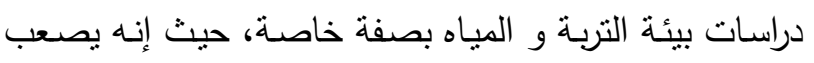
وصف وعرض الخواص المختلفة بدقة عالية نتيجة إلى التباين Webster, ) الكبير في الخواص داخل مساحة الحقل الواحد

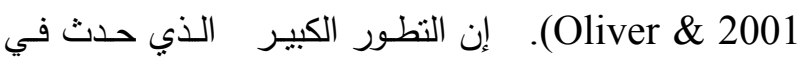
برمجيات نظم المعلومات الجغرافية (GIS) في العقود الأخيرة

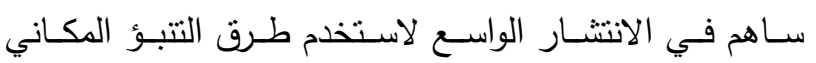
(Burrough, 1986; McDonnell \& Burrough, 1998; Chang, 2002) 
وقام Tunçay وآخرون.،(2016) بتقييم طريقة IDW لرسم

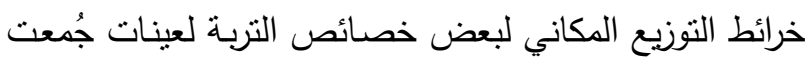

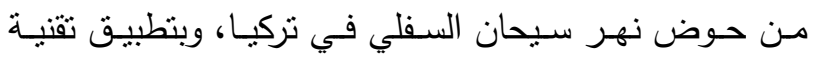

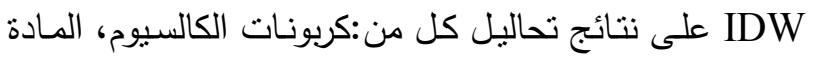
العضوية، السعة التبادلية الكاتيونية، ومحتوى الطين، ووجد أن لن الخصـائص المتنبَّئ بهـا والمتحصـل عليهـا باسـتخدام IDW

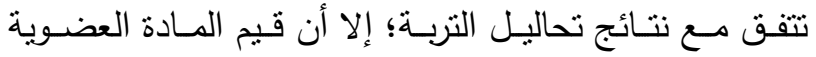
أظهرت خطأ منوسط عالي على خلاف الخصائص المدروسة الخها الأخرى. وأجرى(Nikpeyو آخرون 2017 ) نقييم أداء تقديرات طريقة IDW لإنتاج خرائط لبعض خصـائص نوعيـة التربـة

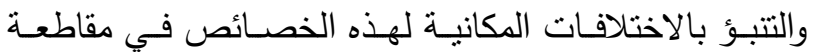
جولستان الواقعة في الجزء الثمالي من إيران، حيث قام بقياس

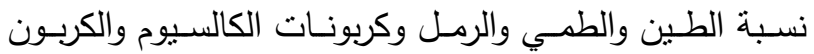
العضوي والجير وتركيزات المغذيات الصـغرى والكبرى و Ec و كتغيرات رئيسة تؤئر على جودة التربة.

ومـن النتائج تبنين أن طريقـة IDW أنتجت أفضـل الخـرائط للتتبؤ بالاختلافـات المكانيـة لكل من:(نسبة الرمـل، الكربـون العضوي، pH والجير ). إن الاختلافات المكانية والزمانية في المحتوى الرطوبي للتربة (GWC) أصبحت تستخدم بكثرة في النــاذج الهيدرولوجيـة والمناخيـة. كــللك اسـتخدام النـــاذج الرياضية لنقدير حركة الماء والأملاح في تربة الحقل أدى إلى الى

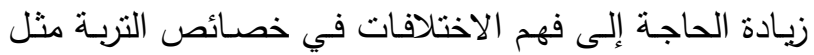
المحتوى الرطوبي (GWC) والكثافة الظاهريـة(BD) وغيرهـا

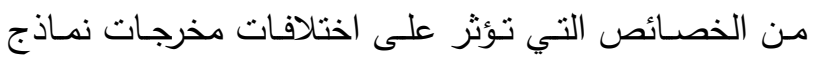
التتبؤ. وبمـا أن الخصـائص الهيدروليكيـة للتربـة تتغاير رأسبياً

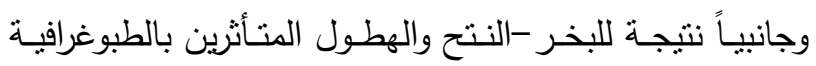
وقوام التربة والغطاء النباتي، لهذا فإن إيجاد طريقة جيدة للتتبؤ

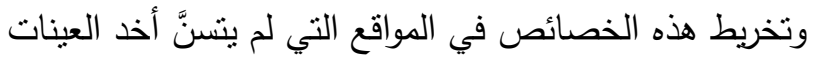

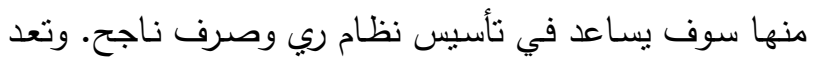

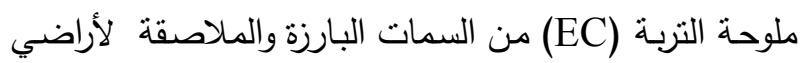

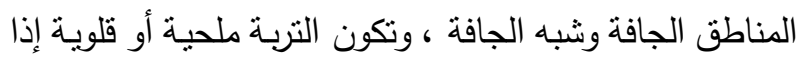

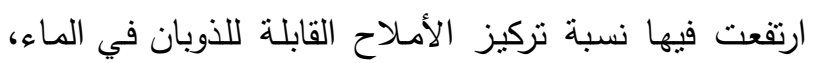

وتعرف طريقة مقلوب المسافة الموزونـة (IDW) بأنها هي طريقـة توليف موضـعي، تعتمـد على توليف المسـافات بـين

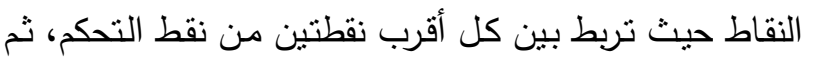
تقدر قيمة النقط بين كل نقطتين على طريقة مقلوب المسافة بينهما، التي تكون موزونة بقيمة المدى بين الحد الأدنى والحد

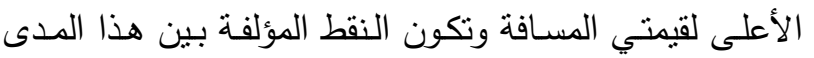
(شرف، 2017) ( )

وقد أظهرت هذه الطريقـة دقتهـا وجودتهـا العاليـة في التتبؤ

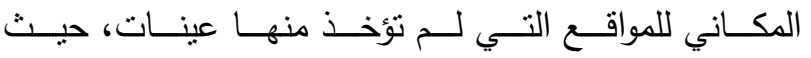

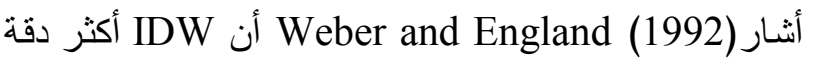

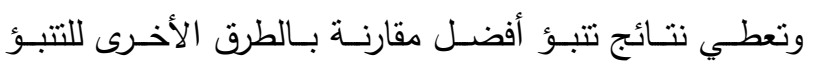

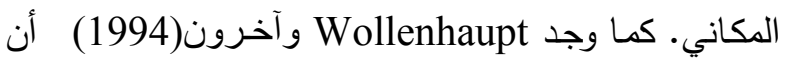
طريقة IDW كانت نتائجها أكثر دقة نسبياً لإنتاج خرائط تربـة مكانيـة لمسـنويات الفسـفور (P) والبوتاسـيـوم (K). ولاحـظـ Gotway مكانية لمحتويات المادة العضوية ومستويات النترات في ترب عدة حقول عند استخدام طريقة IDW. وقد استخدمت معظم

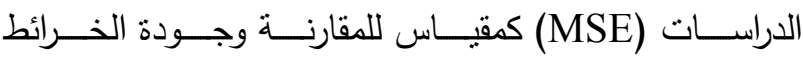
(England and Weber, 1992; Gotway Mabit and Bernard (2010) وآخرون(1996 )ودرس التوزيع المكاني للمادة العضـوية لتربـة حقل زراعي في كندا باستخدام طريقة IDW حيث أعطت الطريقة نتائج جيدة. كما

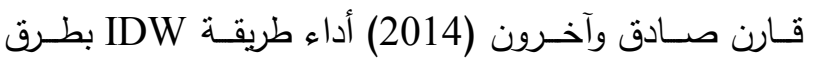

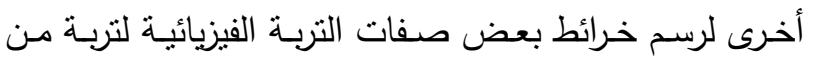

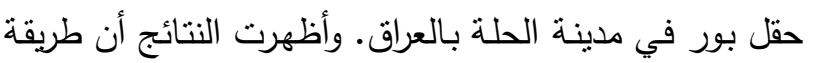

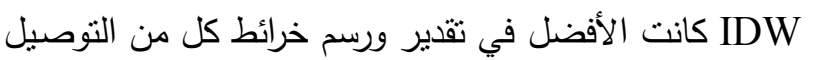
الهيدروليكي التشبعي والمحتوى الرطوبي الحجمي للتربة، بينما كانت طريقة IDW أقل دقة في رسم خريطة الكثافة الظاهرية للتربـة حسب قيم (MSE). وأثـارت جبيـر (2013) إلى أن طريقة IDW أعطت نتائج جيدة لحساب التتبؤ المكاني داخل قطاع التربـة لكل من القوام، الكثافة الظاهرية، ملوحـة التربة،

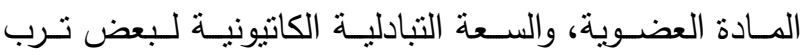
محافظلة صـلاح الدين بـالعراق وذللك حسب قيم (RMSE). 
وبنـاء عليه فـإن نطبيق التتبؤ المكاني في المجالات البيئيـة

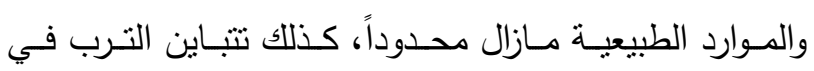
خصائصـها وخواصها من مكان إلى أخر داخل الحقل الواحد حيث يصسب التعرف على هذه الخـواص في جميع أنحساء

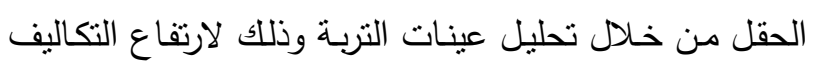
والوقت، من هنا كان من الضروري استعمال طرق تحديد هذه الخواص بأقل تكاليف وفي فترة زمنيـة قصيرة. ولهـذا كـان الهدف من هذه الدراسة نطبيق التتبؤ المكاني بطريقة مقلوب

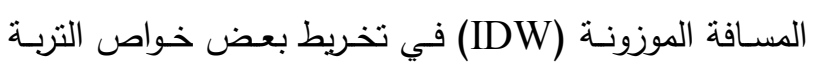

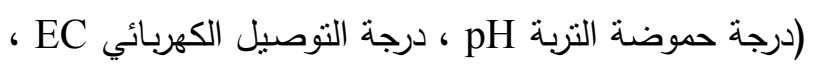

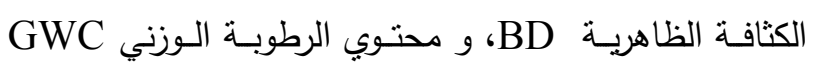

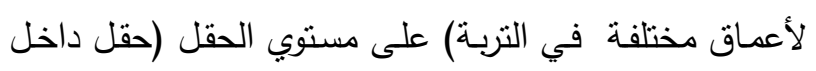

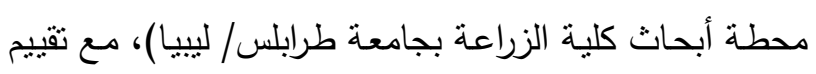

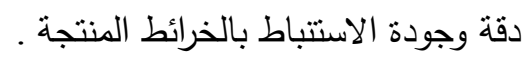

\section{المواد وطرق البحث}

منطقة الدراسة: أجريت هذه الدراسـة بمحطة أبحاث كلية الزراعة في جامعة

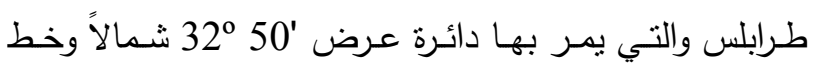

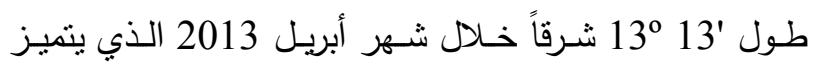

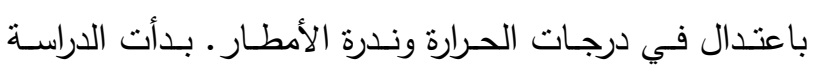
بتحديــد قطعـة أرض مسـطحة مســاحتها 13200 م² تقريبـا منتشرة بها بعض النباتات والأعشاب البريـة ومحاطة بأثجار مصدات الرياح من كل الجهات كما هو موضح بالثكل (1).

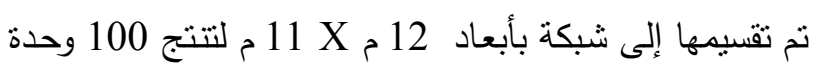

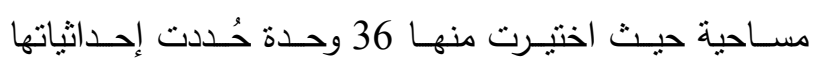

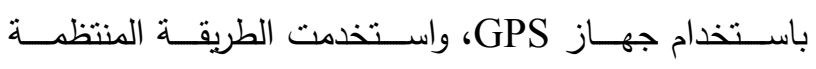
Regular

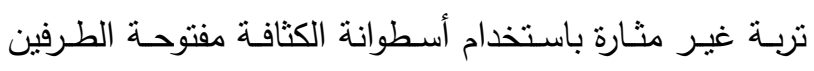

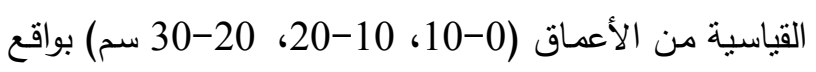
ثلاثة مكرارت لكل عمق وذلك لتحديد كثافة التربـة الظاهريـة

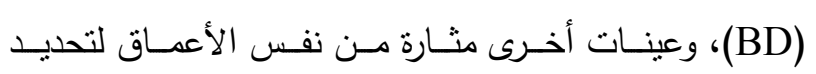

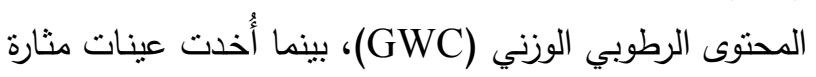

ويعتمد توزيع الأمـلاح المختلفة في التربة على الاختلافات في دي درجة ذوبانها من جهة وشدة عملية الغسيل النهائي وعملية التبخر من جهة آخرى، ولهذا فإن معرفة نركيز الأمـلاح

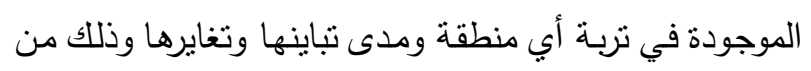

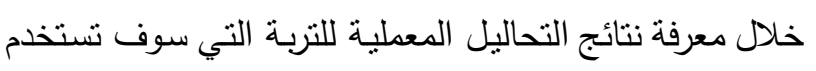

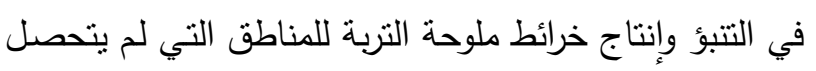
منها على عينات تربة. وبيَّن المحيمد (1999) أن من بين لتئن

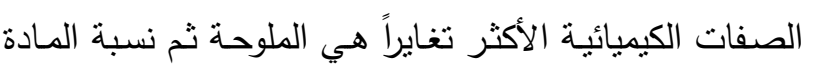

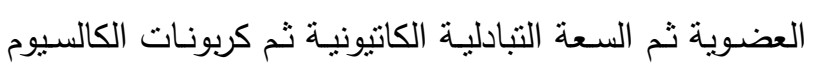

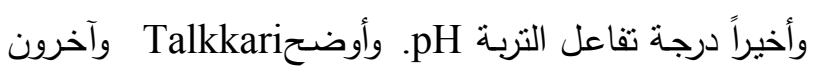

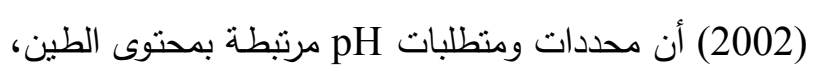
وبيَّن أنسه بانخفاض محتوى الطين تنخفض مسـاحة السطح النوعي وتنخفض كل من السعة التبادلية الكاتيونيـة والكربون

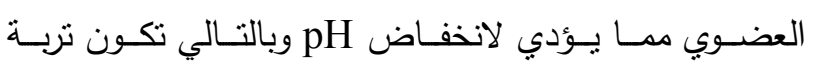
حامضية. أوضح Usowicz وآخرون(2004) أن التغايرات في خواص

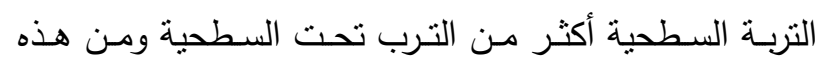
الخواص pH والسعة التبادليـة الكاتيونيـة والكربون العضـوي.

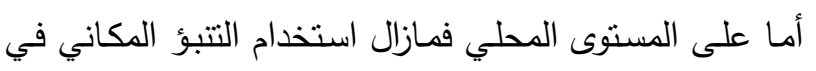
دراسة الاختلافات المكانية في خواص التربة المختلفة محدوداً، حيث استخدم امحمد (2015) طريقة IDW في إنتاج خرائط وتقييم الملوحة لبعض المحاصيل الزراعية في منطقة سواوة

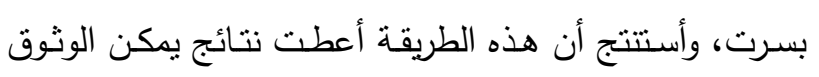

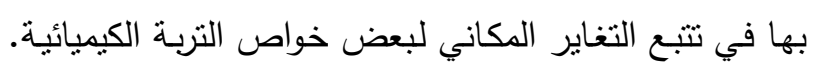

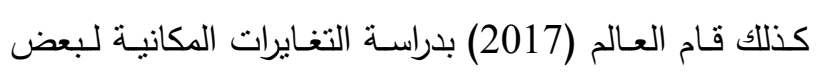

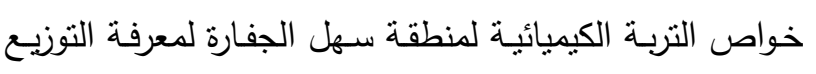

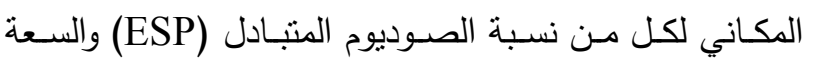

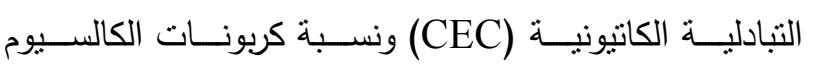

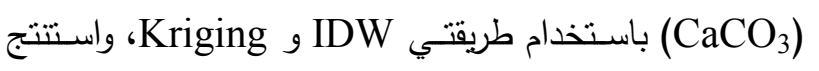

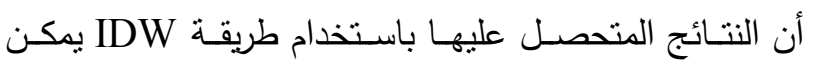

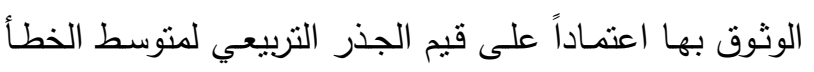
(RMSE) 
ونم تحديد أوزانها الجافة لتقدير المحتوى الرطوبي الوزني للتربة (1996 وآخرون Arshad )

قياس درجة حموضـة التربـة وتوصيلها الكهريائي: تم تجهيز

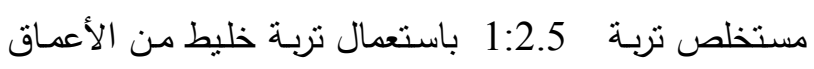

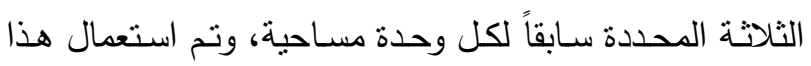
المستخلص لقياس pH و pC للتربة بواسطة جهازي ميتز (1993 وآخرون EC

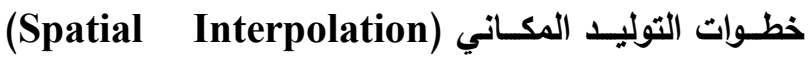
بطريقة مقلوب المسافة الموزونـة (IDW): تم استخدام أحد

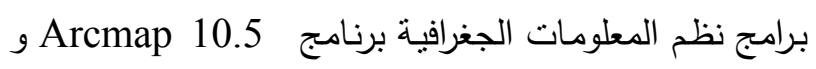

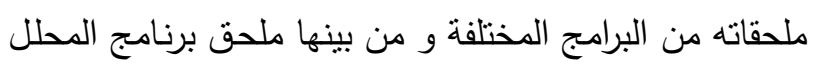
الإحصائي (Geostatistical Analyst) وذللك لاستخدامها في عمليـات التحليل الإحصـائي الوصفي والمكاني للبيانـات

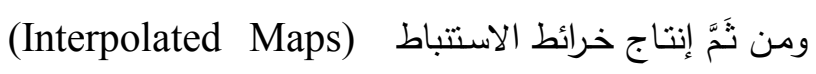

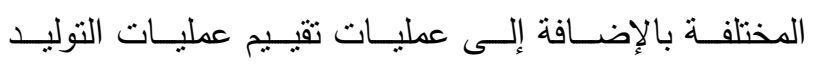
Interpolation الرطوبي الوزني، درجـة التفاعل، ودرجـة التوصيل الكهربـي) (Rosenbaum and Söderström.1996)

ويتم في هذه الطريقة تقدير قيم للنقاط غير المقيسة مستخدما

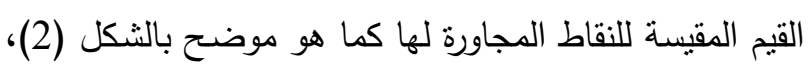

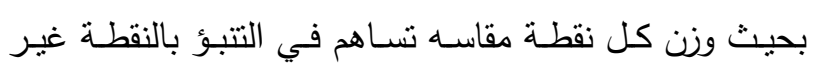

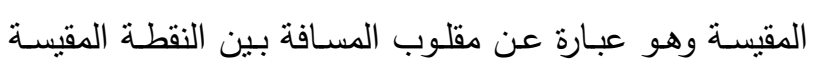

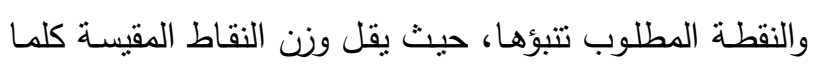
كانت بعيدة عن النقطة الغير مقاسه والمطلوب توليدها. وتتأثز

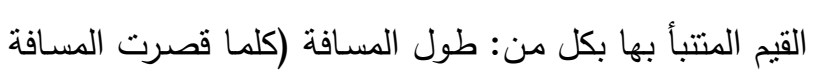

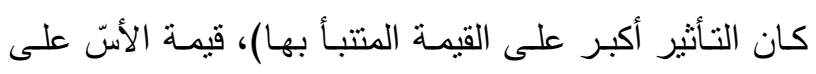

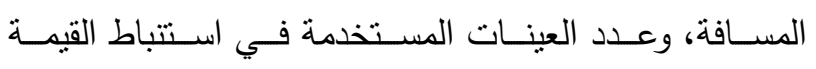
المسـتبطة. و حسب Peterson (2017) فالمعادلـة التاليـة

تستخدم في حساب القيم المستتبطة في طريقة IDW :

$$
z(\mathbf{x})=\sum_{i} w_{i} z_{i} / \sum_{i} w_{i}
$$

بعدق 30 سم لتقدير ملوحة التربـة (EC) ودرجـة حموضتها $\cdot(\mathrm{pH})$
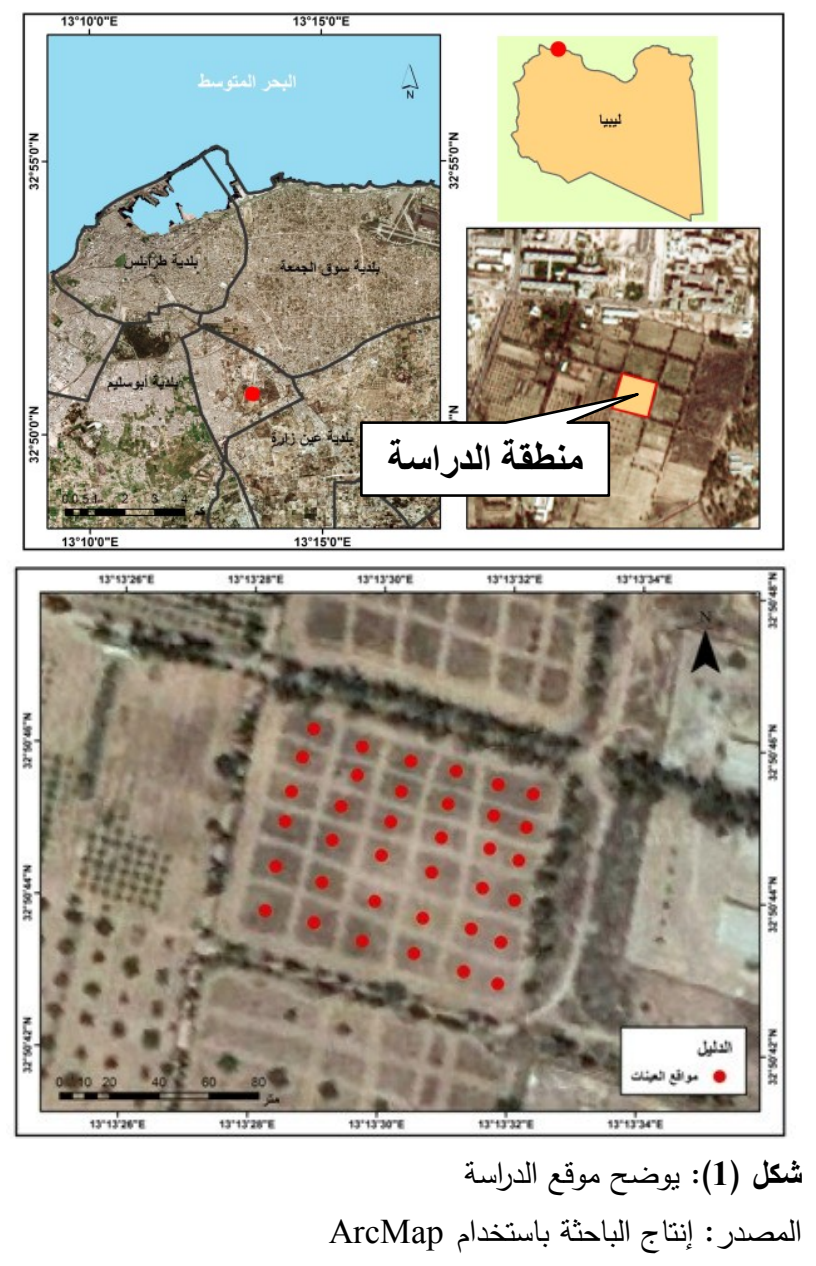

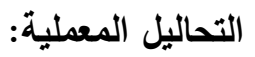
قيـاس الكثافـة الظاهريـة: تم تقدير الكثافة الظاهريـة بطريقة

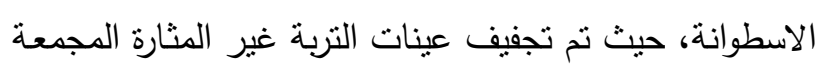

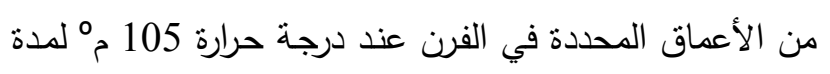

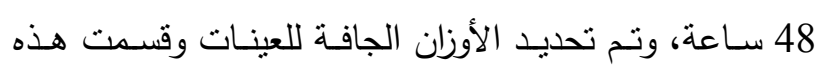

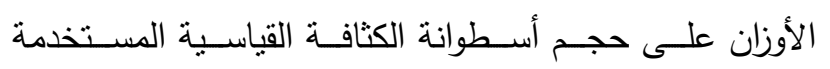
.(Carter \& Ball, 1993)

قياس المحتوى الرطويي: تم تقدير المحتوى الرطوبي بالطريقة

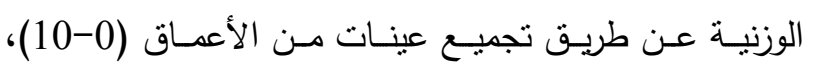

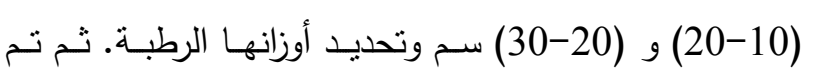

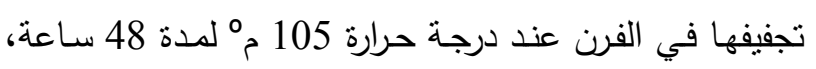




\section{النتائج والمناقشة}

أظهرت نتائج قياسـات التربـة والتحاليل الإحصـائية الموضحة

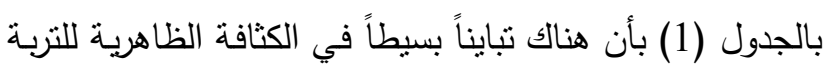

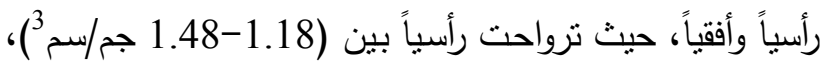

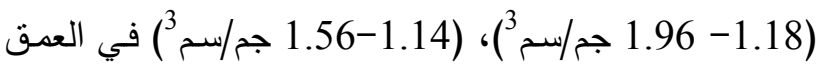

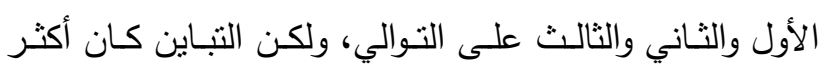

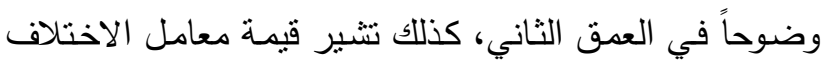
(CV= \%9)

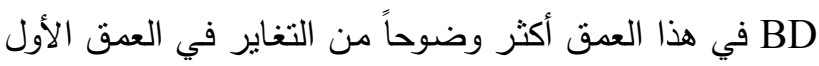

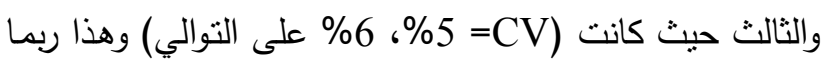
يعزى إلى أن BD في العمق الأول أقل تغايراً أو تبايناً مقارنة

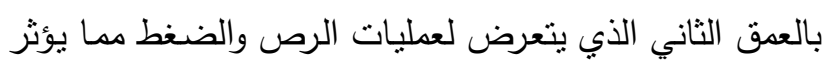
على قيم BD، ونتقف هذه النتائج مـع ماوجده (2005 وآخرون

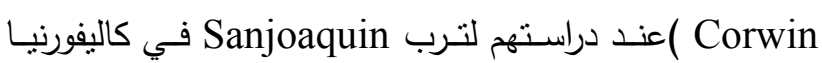
حيث وجدوا أن BD أقل تغايراً في الآفـاق السطحية مقارنـة

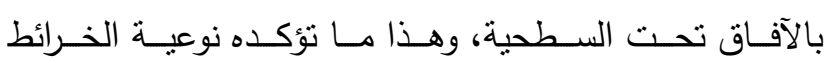

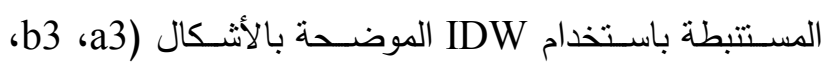
(c3)، حيث تشـير قيم RMSE المنخفضـة في العمـق الأول

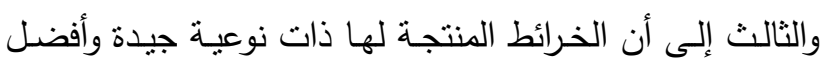
نوعاً ما من تللك الخرائط المستتبطة للعمق الثاني. كذللك يتبين

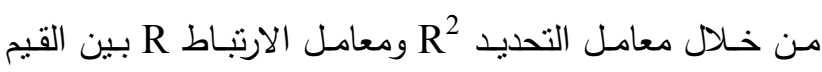

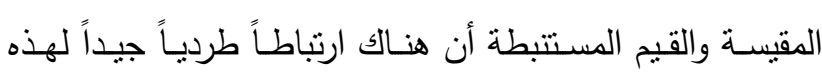

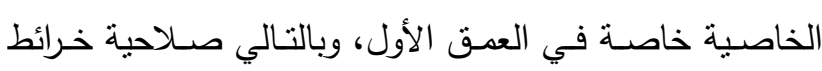

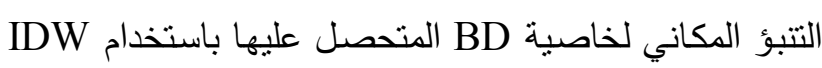

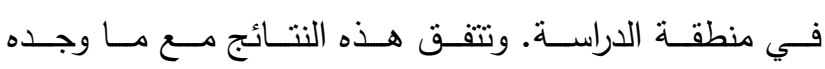
فوBogunović فـروق معنويـة في BD مـع العمـق، كذللك أثــار لقيم CV

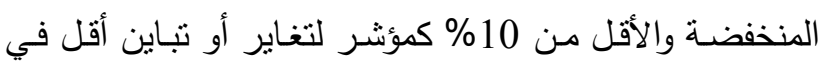
دراسته. بينما توصل صادق وآخرون (2014) إلى ان الخرائط المنتجة لخاصية BD أقل دقة باستخدام طريقة IDW نتيجة

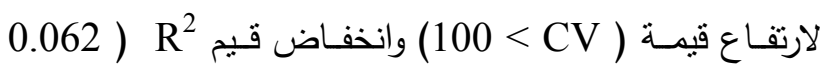

$$
w_{i}=1 / d_{i}^{2}
$$

Z : النقطة المراد استتباطها أو التتبؤ بها Zi الم $d^{2} i$ التتبؤ بها wi

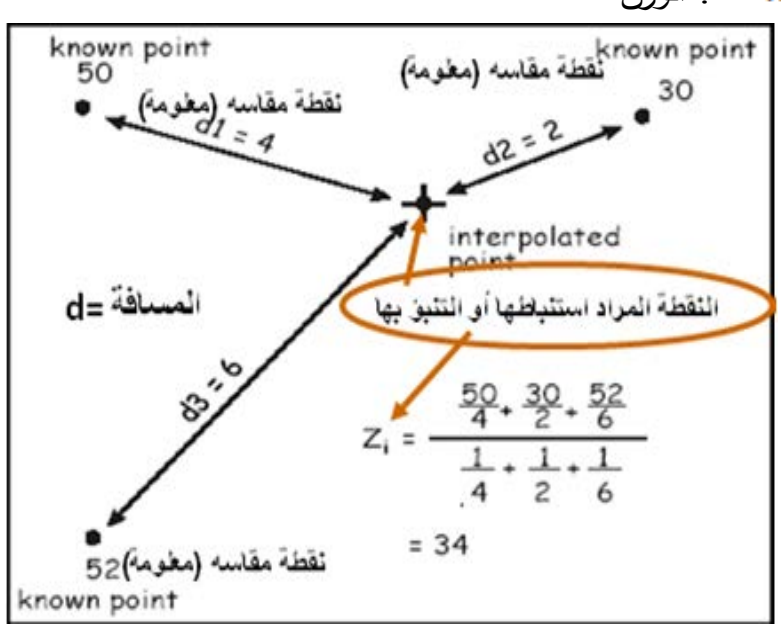

شكل (2) يوضح طريقة حساب قيم غير معلومة مستخدماً قيم معلومة

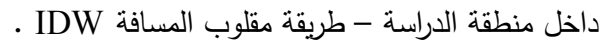
Vineeth et al., (n.d) : المصدر

وبعـد إنتاج الخرائط لكل الخصـائص المدروسـة مـن النتـائج

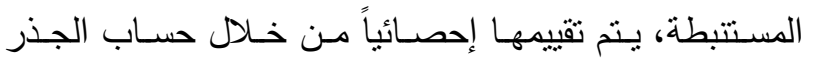
التربيعي لمتوسط مربع الخطأ RMSE الذي ينأثر بقيمة أُسّ المسافة لتحديد الوزن المشار إليها في المعادلة 2، وكلما كانت

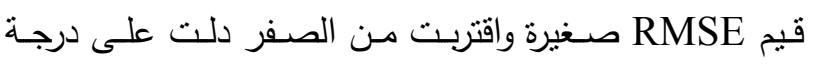
عالية من الثقة في عملية الاستتباط، والدقة في خرائط التتبؤ

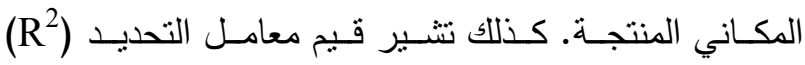

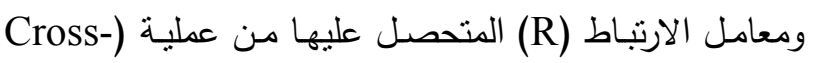
(Validation المستتبطة المتحصل عليها، حيث تم في هذه العملية استخدام

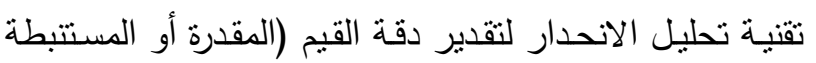

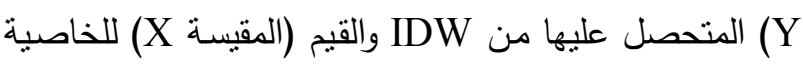
المدروسة. 
جدول: (1) النحليل الإحصائي لييانات الخرائط المكانية المنتجة لخواص التربة المدروسة

\begin{tabular}{|c|c|c|c|c|c|c|c|}
\hline$\% \mathrm{CV}$ & $\mathrm{R}$ & $\mathrm{R}^{2}$ & RMSE & Max & Min & الأعماق (سم) & الخواص \\
\hline 5 & 0.55 & 0.30 & 0.06 & 1.48 & 1.18 & $10-0$ & \\
\hline 9 & 0.47 & 0.22 & 0.13 & 1.96 & 1.18 & $20-10$ & BD (جم/سم3) BD \\
\hline 6 & 0.46 & 0.21 & 0.07 & 1.56 & 1.14 & $30-20$ & \\
\hline 29 & 0.56 & 0.31 & 0.71 & 3.98 & 1.03 & $10-0$ & (\%) GWC \\
\hline 30 & 0.45 & 0.20 & 0.82 & 4.25 & 1.19 & $20-10$ & \\
\hline 39 & 0.45 & 0.20 & 0.86 & 4.60 & 1.20 & $30-20$ & \\
\hline 35 & 0.81 & 0.65 & 0.84 & 0.64 & 0.16 & $30-0$ & EC (مليموز/سم)) EC \\
\hline 3 & 0.66 & 0.44 & 0.15 & 8.1 & 7.4 & $30-0$ & $\mathrm{pH}$ \\
\hline
\end{tabular}

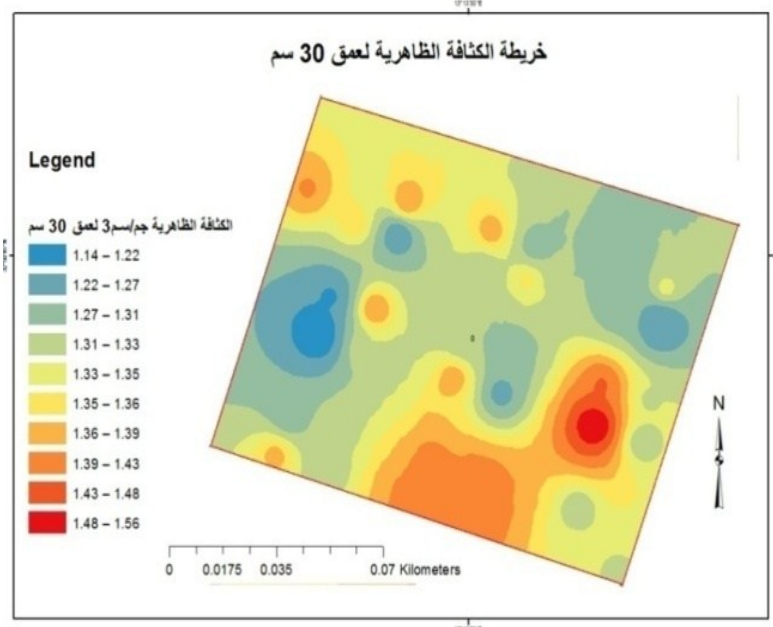

شكل (3c): الخريطة المستتبطة للكثافة الظاهرية للعمق الثالث

أما بالنسبة للتغاير في المحتوى الرطوبي الوزني GWC كما هو موضح بالأشكال (a4، b4، c4) يبدو واضحاً من النتائج

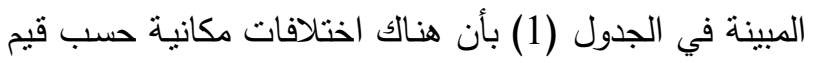

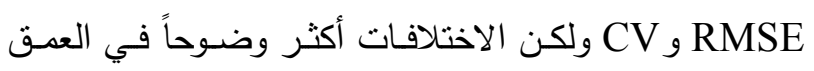

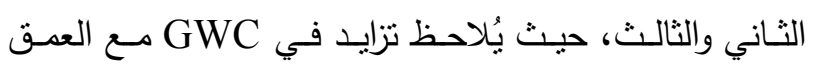
مقارنة بالعمق الأول الذي تنخفض فيه GWC نتيجة للبخر

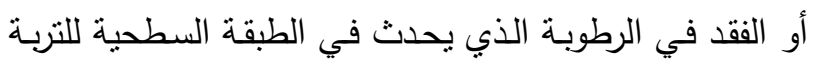

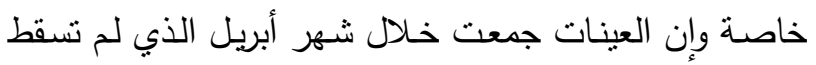

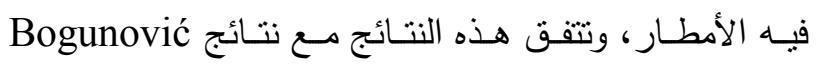

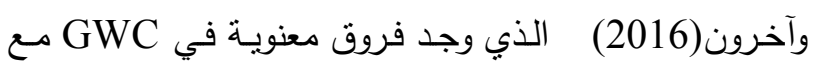
العمق كذلك وجد انخفاض معنوي في GWC في العمق 010 ، كما وجد( Moradi وآخرون 2012) اختلافات مكانية

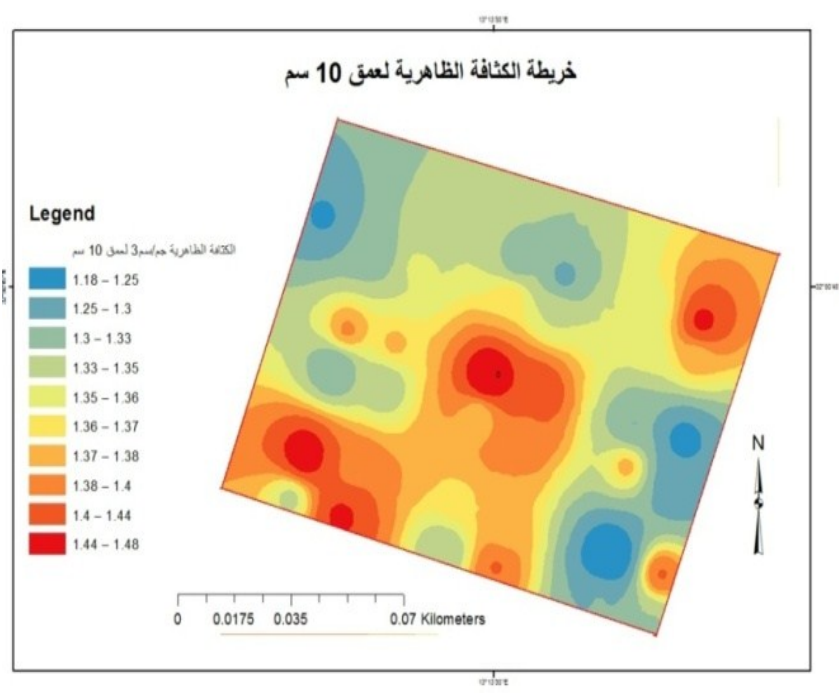

شكل (3a): الخريطة المستتبطة للكثافة الظاهرية للعمق الأول

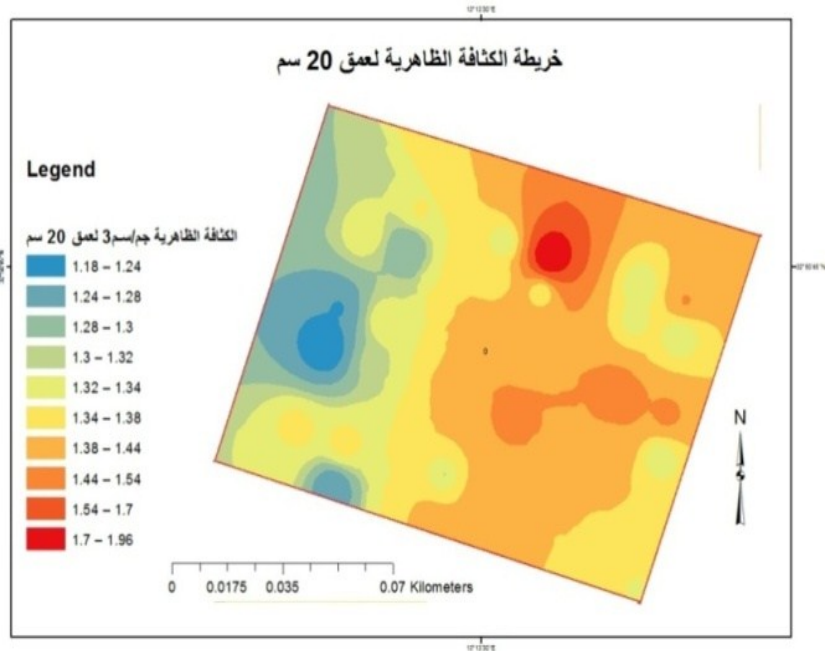

شكل (3b): الخريطة المستتبطة للكثافة الظاهرية للعمق الثاني 


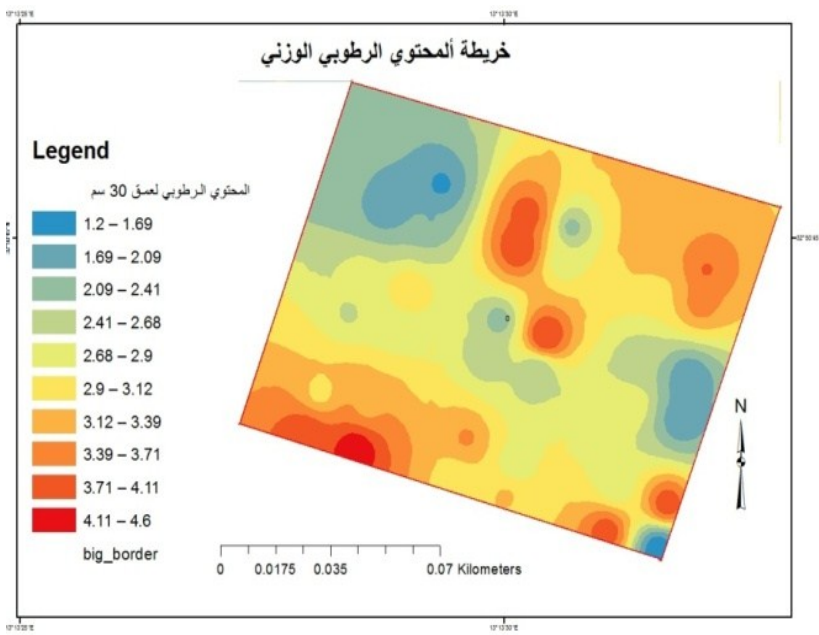

شكل (4c): الخريطة المستتبطة للمحتوى الرطوبي الوزني للعمق الثالث

يوضح شكل (5) الخريطة المستتبطة لملوحة التربة والتي يعبر عنها بالتوصيل الكهربائي EC، وتصف هذه الخريطة التغاير

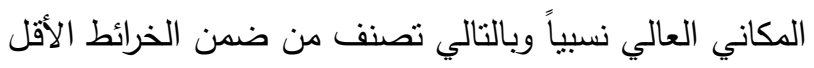

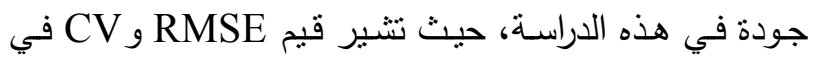

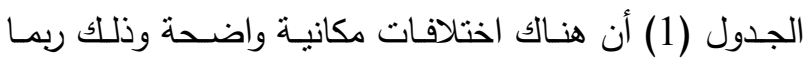

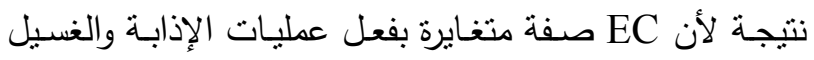

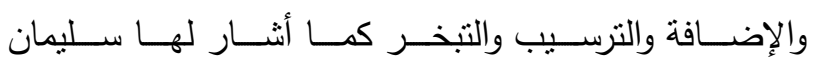
وجيير (2014). وتتفق هذه النتائج مـع مـا وجده المحيميد (1999) إذ وجد أن من بين الصفات الكيميائية الأعلى تغايراً هي الملوحة عند دراسته لتغاير قيم EC لترب رسوبية عراقية،

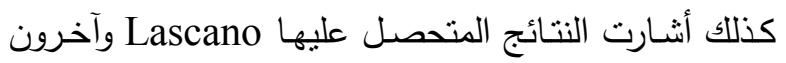
(2001) عند دراسته لترب في أمريكا أن تغاير الملوحة كان عالياً مقارنة بالخواص الأخرى. على خلاف ذللك تعتبر درجة تفاعل التربة pH أقل الخواص تغايراً حسب النتائج الموضحة بالجدول (1)، حيث نوضح قيمة CV المنخفضة مقارنة بتلك الخواص الأخرى أن الاختلافات المكانية ضئيلة، كذلك تشير

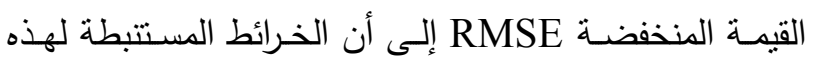

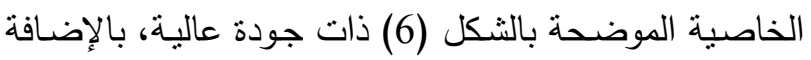
لارتفاع قيم معامل التحديد R2 ومعامل الارتباط R بين القيم

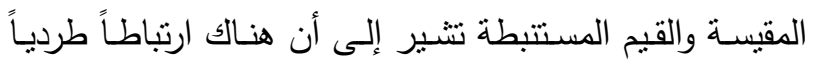
جيداً لهذه الخاصية، أي إن القيم المستتبطة لا تتحرف كثيراً

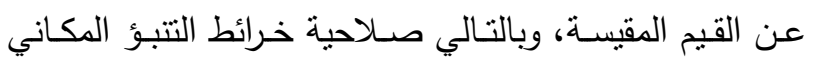

واضحة في GWC عند الأعماق المختلفة قبل الري وبعده، وبشكل عام تعتبر الخرائط المستتبطة لخاصية GWC أقل جودة من تلك المستتبطة لخاصية BD حسب قيم و ولكن كانت أفضل من نتائج Bogunović وآخرون

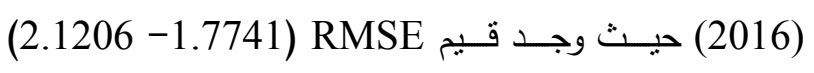
للأعمــاق (0-10 ، 10-20) علــى التــوالي عنــد دراســة الاختلافات المكانية لخاصية GWC، كذلك ارتفاع قيم معامل

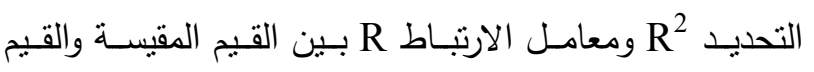
المستتبطة في العمق الأول نتير إلى أن هنالك ارتباطاً جيداً

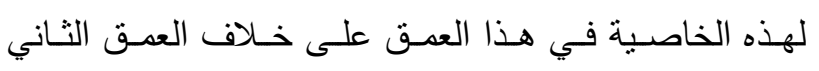

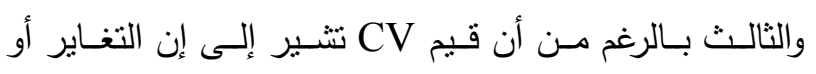

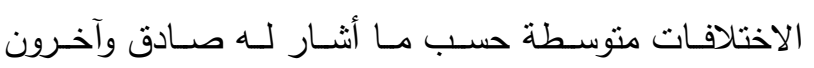

$$
\text { .(CV=15\%-50\%) (2014) }
$$

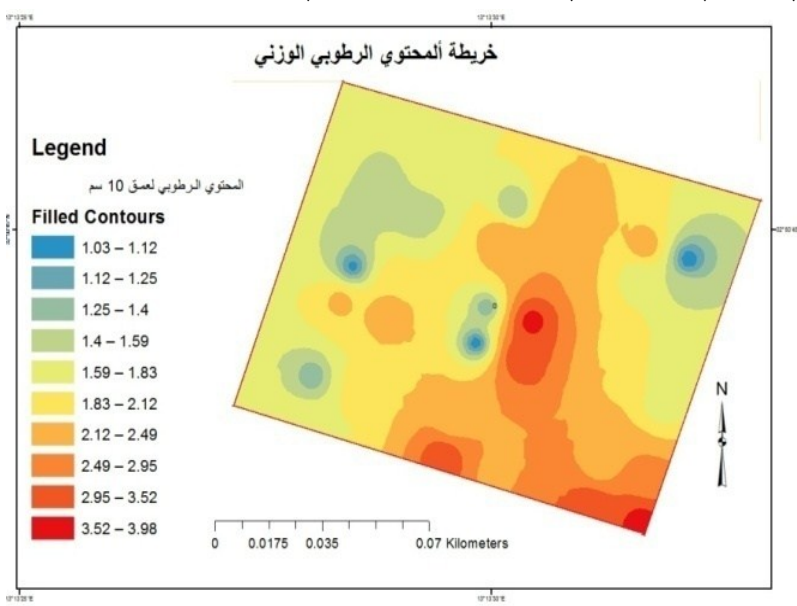

شكل (4a): الخربطة المستتبطة للمحتوى الرطوبي الوزني للعمق الاول

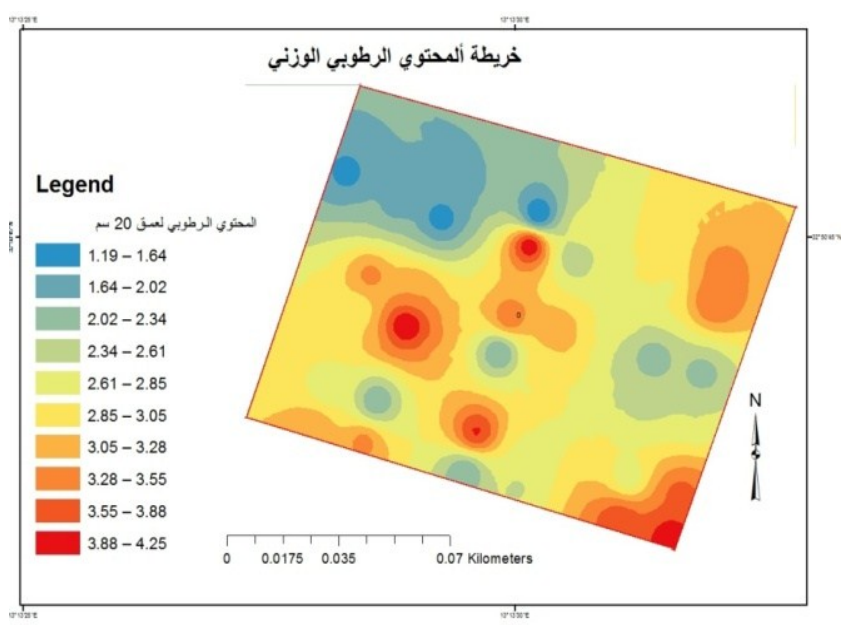

شكل (4b): الخريطة المستنبطة للمحتوى الرطوبي الوزني للعمق الثاني 
وبنـاء بيئة إيكولوجيـة محددة. ويُعَدُ استخدام الأرض وإدارتها

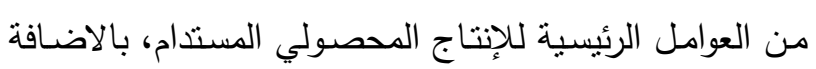

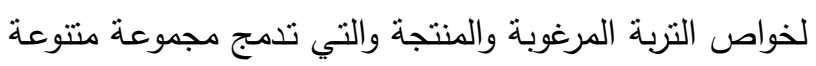
من العمليات البيئية والممارسات البشرية في الوسط الطبيعي.

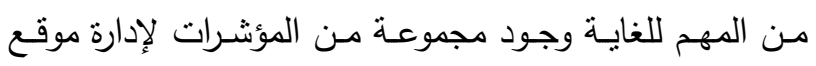

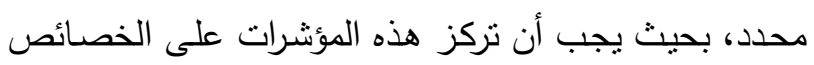

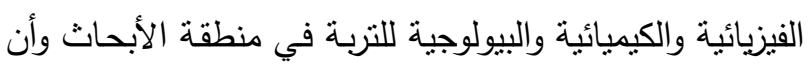
تكون مستهدفة. ركزت هذه الورقـة على استخدام الإحصـاء

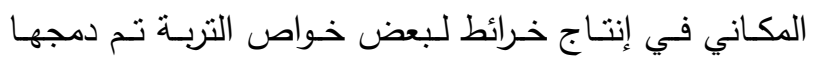

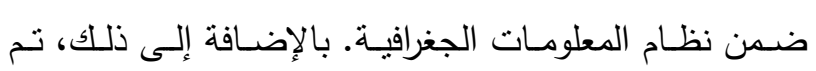

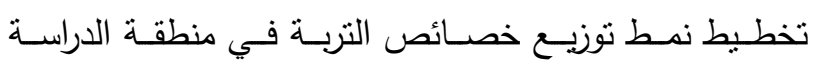

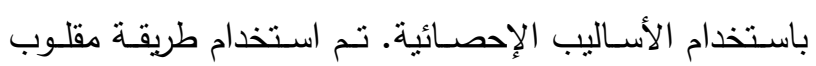

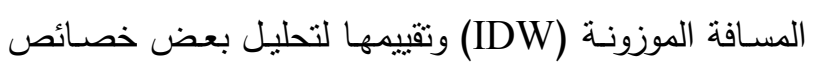

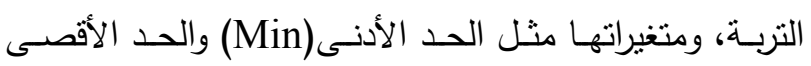

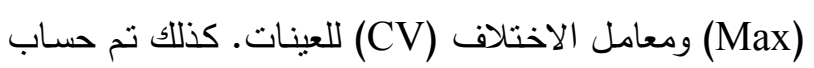

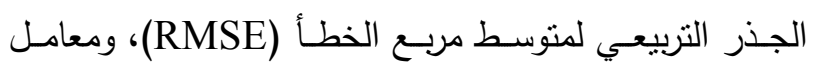

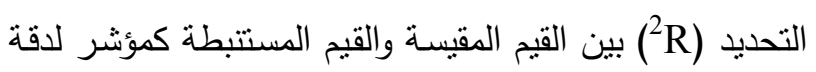

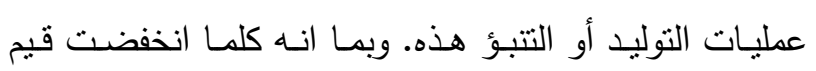

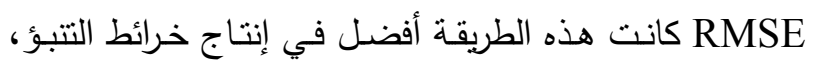
عليه نستتج ان طريقة IDW في هذه الدراسـة أعطت نتائج

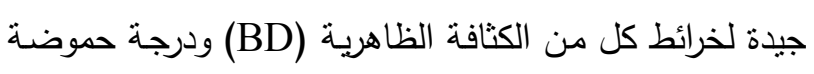
التربـة (pH)، وبالتالي يمكن ان تنتخدم هذه القيم التي تم

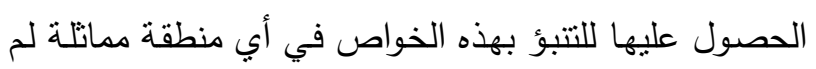

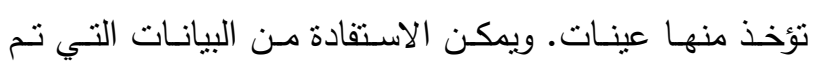

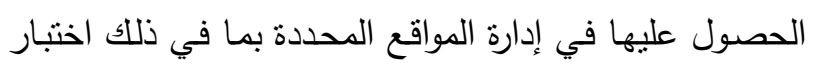

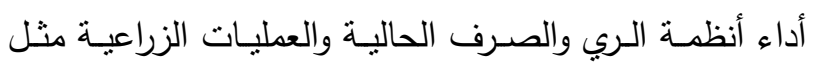

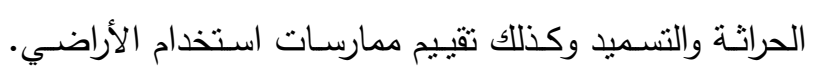
بينما خرائط المحتوى الرطوبي الوزني (GWC) وملوحة التربة ولتية

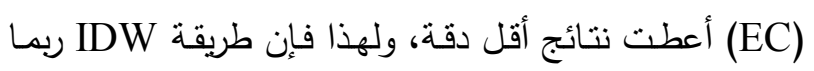

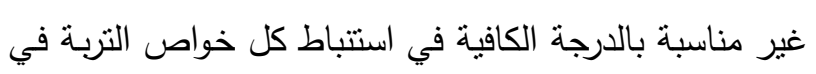
هذه الدراسة وعليه يجب استخدام طرق أخرى منل فئل للحصول على نتائج أفضل بشرط زيادة عدد العينات ومقارنتها

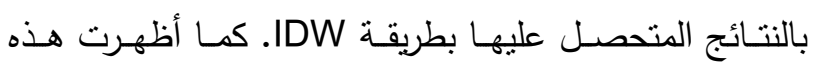

لخاصية pH المتحصل عليها باستخدام IDW في منطقة

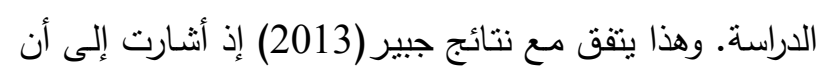

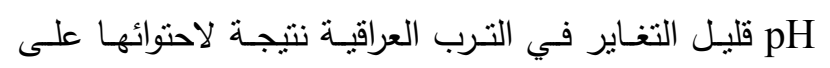

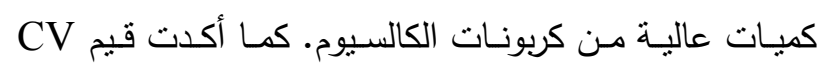
المنخفضة لخاصية pH في التربة بأنها أقل الخواص تغايراً،

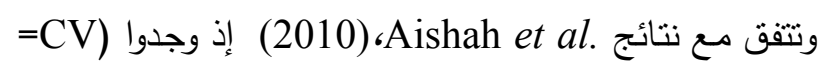

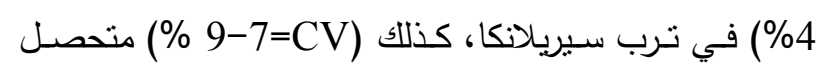
عليها من قبل Usowicz \& Lipiec (2017) في الترب
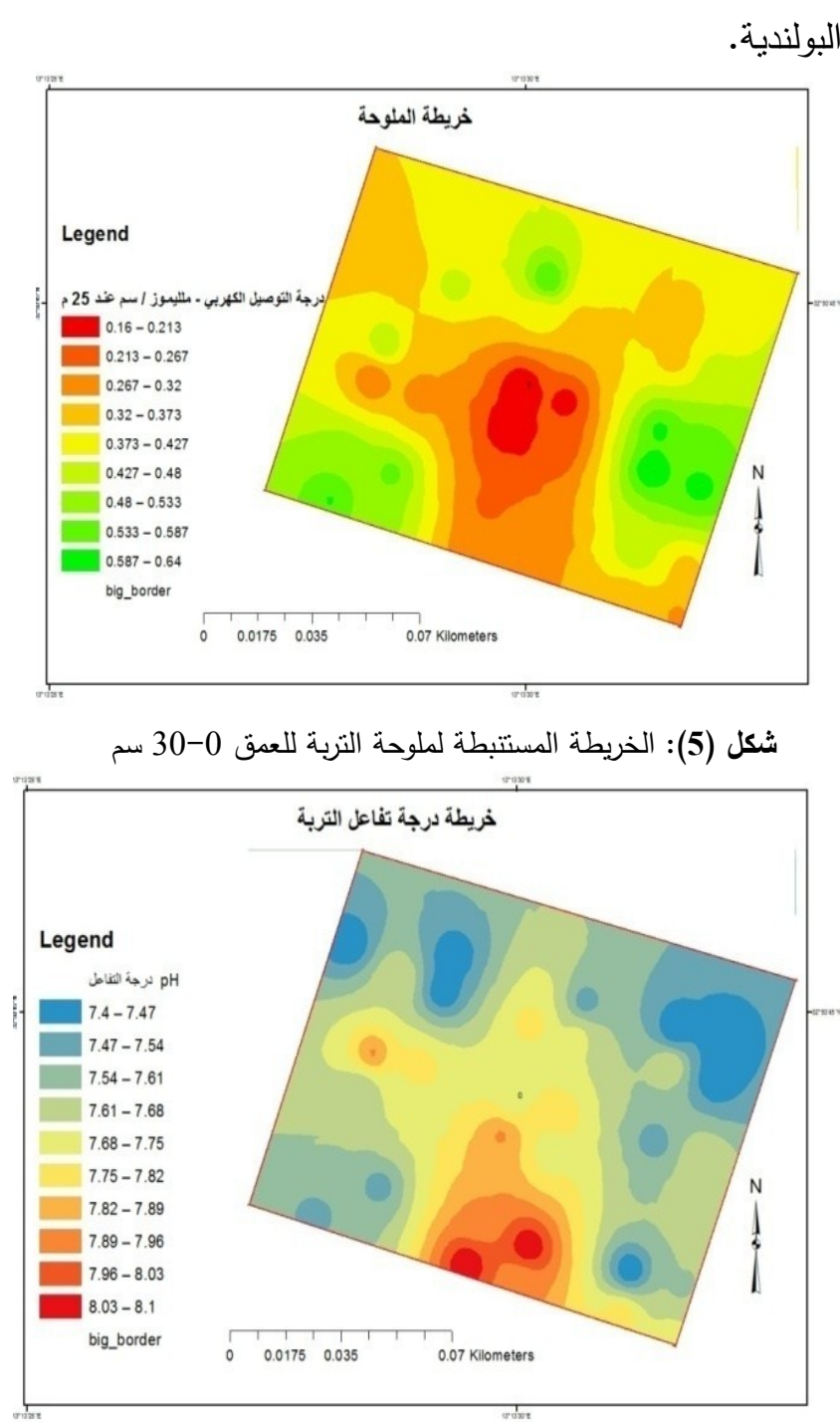

شكل(6): الخريطة المستتبطة لدرجة تفاعل التربة للعمق 0-30 سم

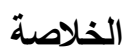

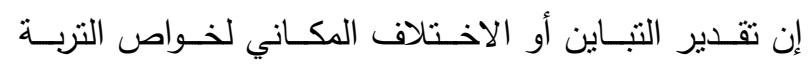
الفيزيائيـة والكيميائيـة شـرط أساسـي لإدارة التربـة والمحاصـيل 


$$
\begin{aligned}
& \text { الإحصـاء البيـدولوجي. مجلـة جامعـة تكريـت للعلـوم } \\
& \text { الزراعية. } 14 \text { (1): 236-245. } \\
& \text { شـرف. محمـــــــراهيم محمـــ. (2017). المرجـع في نظـم }
\end{aligned}
$$

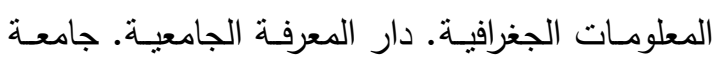

$$
\begin{aligned}
& \text { الاسكندرية، مصر • ص } 328 . \\
& \text { صـادق، منير هاشم؛ هادي عبد الأمير العجيلي وسعد شاكر } \\
& \text { العزاوي. (2014). دراسـة مقارنة تقنيات التقدير لرسم }
\end{aligned}
$$

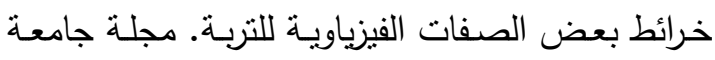

$$
\begin{aligned}
& \text { كربلاء. } 12 \text { (2): 221-232. }
\end{aligned}
$$

Aishah, A.W.; Zauyah. S; Anuar. A.R; and Fauziah.C.I . (2010). Spatial variability of selected chemical characteristics of padoly Soils in Sawah Sempadan, Selangor ,Malaysia. Malaysian J of soil Sci, vol.14:27 -39

Arshad, M.A.; B. Lowery and B. Grossman (1996). Physical tests for monitoring soil quality. In: Doran, J.W. and A.J. Jones (Eds). Methods for assessing soil quality. SSSA Spec. Publ. 49. Soil Science Society of America, Inc., Madison, Wisconsin, USA, p.123-142.

Bogunović, I., Dekemati, I., Magdić, I., Vrbanić, M., Matošić, S., Mesić, M. (2016). Spatial modeling for describing spatial variability of soil physical properties in eastern Croatia. Poljoprivreda,22: 2016 (1) 46-52.

Burrough, P. A. (1989). Fuzzy Mathematical Methods for Soil Survey and Land Evaluation. Journal of Soil Science, 40: 447492.

Burrough, P. A. (1993). Problems of Superim Posed Effects in The Statistical Study of The Spatial Variation of Soil Agricultural .Water Management, Netherlands, 6: 123 $-143$.
الدراسـة أهميـة تأسيس قاعدة بيانـات مكانيـة لخصـائص تربـة

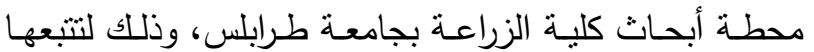
مكانياً وزمانياً في الدراسات المستقبلية.

\section{المراجع}

$$
\begin{aligned}
& \text { امحمد، مفتاح علي محمد. (2015). تقيبم وتخريط ملوحـة }
\end{aligned}
$$

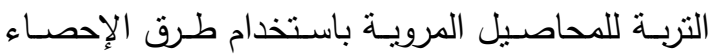

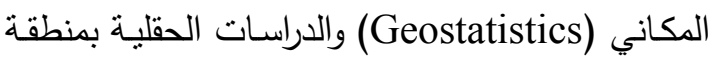

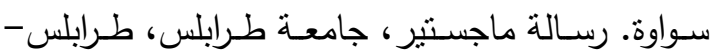

$$
\begin{aligned}
& \text { ليبيا. }
\end{aligned}
$$$$
\text { الجبوري، ثاير حبيب؛ منعم نصيف جاسم المزروعي ومنذر }
$$

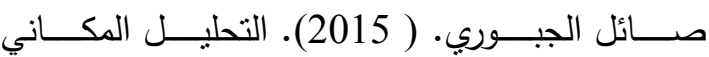$$
\text { لخصائص ترب ناحية المنصورية. مجلة ديالي. (65): }
$$$$
.84-58
$$

$$
\begin{aligned}
& \text { العـالم، مختـار محمـود. (2017). التغـايرات المكانيـة لبعض } \\
& \text { خواص التربـة الكيميائيـة لمنطقـة ســل الجفـارة (حالـة } \\
& \text { دراسية: طرابلس، وادي المجينين، بن غشبر). المجلة } \\
& \text { الليبية للعلوم الزراعية. } 22 \text { (1): 19-34. } \\
& \text { المحميـد، عبـد الحلـيم علـي سـليمان. (1999). التغـايرات } \\
& \text { المكانية والزمنية لبعض صفات الترب في وسط السـل } \\
& \text { الرسـوبي العراقـي - اطروحـة دكتوراه-كليـة الزراعـة } \\
& \text { جامعة بغداد. } \\
& \text { جبير ، أمسل راضـي. (2013). دراسـة التغـايرات المكانيـة } \\
& \text { واستحصـال العينـات لبعض صـفات التربـة في شـمال }
\end{aligned}
$$

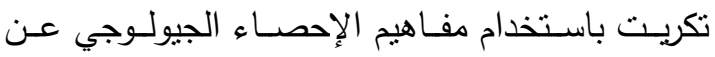

$$
\begin{aligned}
& \text { طربـق المعلومـات الجغرافيـة (GIS). مجلــة الفـرات } \\
& \text { الزراعية. } 5 \text { (3): 268-279. }
\end{aligned}
$$

سليمان. عبد الحليم علي وأمل راضي جبير • (2014). دراسة التغايرات المكانية لبعض الصفات الفيزيائية والكيميائية للتربـة في وسـط الســل الرسـوبي باسـتخدام مفــاهيم 
Fahad, A. A.; Shib, R. M.; Al-Siaykaly, A. A. and Razaq, I. B. (1993). Spatial Variability of Field Soil Salinity Using Geostatistical Techniques. Basra, Journal Agricultural Science, 6 (1).

Gotway, C. A; Ferguson, R. B; Hergert, G. W; and Peterson, T.A .(1996). Comparison of kriging and inverse-distance methods for mapping soil parameters. Soil Science Society of America Journal ,60: 12371247.

Hendershort, W.H.; H. Lalande and M. Duquette (1993). Soil reaction and exchangeable acidity. In: Carter. M.R. (Eds). Soil Sampling and methods of soil analysis (pp. 141-145). Canadian Soc. Soil Sci., Lewis Publishers London.

Hosseini, E.; Gallich, J. and Marcot, D. (2009). Theoretical and Experimental Performance of Spatial Interpolation Methods for Soil salinity analysis. Transactions of the American Society of Agricultural and Biological Engineers, 37:1799 - 1907.

Hudnall W.; A.Bekele. (2006). Spatial Variability of soil chemical properties of a prairieforest transition in Louisiana. Plant Soil, v. 280, p. 7-21.

Krasilinkov,P.; F.Carre; L. Montanarella. (2008). Soil geography and geostatistics.

Lascano ,R.J. and Hatfield. J.L.(2001). Spatial variability of evaporation long two transects of a bare soil .Soil Sci.Soc Am.J. $56: 341-346$.

Mabit, L. and Bernard C .(2010). Spatial distribution and content of soil organic matter in an agricultural field in eastern Canada, as estimated from geostatistical tools. Earth Surface Process and Landforms, 35: 278- 283
Burrough, P. A., and McDonnell. R. A. (1998). Principles of Geographic Information Systems. Oxford, Oxford University Press.

Burrough, P.A. (1986). Principles of Geographic Information Systems for Land Resources Assessment. Oxford, Oxford University Press.

Camachu, T.; Jesus, H.; Luengas C. A. and Fabio R. L. (2009). Effect of Agricultural Intervention on the Spatial Variability of Some Soils Chemical Properties in the Eastern Plains of Colombia. Chilean Journal of Agricultural Research 68(1): $42-55$.

Carter, M.R. and B.C. Ball (1993). Soil porosity. In: Carter, M. R (Eds). Soil sampling and methods of analysis. Canadian Society of soil science. Lewis Publishers. ISBN 0-87371-861-5.

Chang, K. (2002). Introduction to Geographic Information Systems McGraw-Hill, New York.

Chile`s, J. P. and Delfiner, P. (1999). Geostatistics: Modeling Spatial Uncertainty. John Wiley \& Sons, Inc., New York.

Corwin, D.L. and Lesch, S. M. (2005). Characterizing Soil Spatial Variability with Apparent Soil Electrical Conductivity Part 11. Case Study .Computers and Electronics in Agriculture, 46:135 -152.

De la Rosa, D. (1979). Relation of Several Pedological Characteristics to Engineering Qualities of Soil. Journal of Soil Science, 30: $793-799$.

ESRI. (2012). Environmental Systems Research Institute, Using ArcGIS geostatistical analyst USA. 
Variability of Selected Soil Properties in the Cukurova Plain. Journal of Agricultural Sciences. 22: 377-384.

Usowicz, B.; Hajnos, M.; Sokololwska, Z.; J.zefaciuk, G.; Bowanko, G. and Kossowski, J. (2004). Spatial Variability of Physical and Chemical Soil Properties in a Field and Commune Scale. Acta Agrophys, 3:5 - 90 .

Usowicz,B. and Lipiec, J. (2017). Spatial variability of soil properties and cereal yield in a cultivated field on sandy soil. Soil \& Tillage Research 174 :241-250.

Uyan, M. and Cay, T. (2010). Geostatistical methods for mapping groundwater nitrate concentrations. Paper presented at the $3^{\text {rd }}$ international conference on cartography and GIS. Nessebar, Bulgaria.

Vineeth, P.; Teja. K. and Raghuveer.D. (n.d) https:/www.slideshare.net/penchalavinee th/inverse-distance-weighting

Weber,D., and E.J. England, (1992). Evaluation and comparison of spatial interpolations.Math. Geol., 26: 381-391

Webster, R., and Oliver. M. (2001). Geostatistics for Environmental Scientists John Wiley \& Sons, Chichester.

White, J. G.; Welch, R. M. and Norvell, W. A. (1997). Soil Zinc Map of USA Using Geostatististics and Geographic Information System. Soil Science Society of America Journal, 61:185 -194.

Wollenhaupt, N.C., Wolkowski. R.P, and Clayton, M.K. (1994). Mapping soil test phosphorous and potassium for variablerate fertilizer application. J. Prod. Agric, 7: $441-448$
Mardia, K. V. and Jupp, P. F. 2000. Directional Statistics. John Wiley \& Sons, Ltd, Chichester.

Moradi, M., D. Ghonchehpour, A. Majidi, and V.M. Nejad.(2012). Geostatistic approaches for investigating of soil hydraulic conductivity in Shahrekord Plain, Iran. Amer. J. Math. And statistics 2(6): 164168.

Mulla, D. J. (1997). Geostatistics, remote sensing and precision farming. In: Precision Agriculture: Spatial and Temporal Variability of Environmental Quality. John Wiley \& Sons, Ltd, Chichester.

Nikpey M, Sedighkia M, and Nateghi M B (2017). Comparison of Spatial Interpolation Methods for Mapping the Qualitative Properties of Soil. Advances in Agricultural Science, 5: 1-15.

Peterson, M. (2017). Advances in Cartography and GIScience. Selection from the International Cartographic Conference 2017. Washington.

Rosenbaum, M.; and Söderstoröm, M. (1996).Geostatistices as an aid to mapping. In 1996 ESRI European User Conference. London, UK.

Santra, P.; Chopra, U. K. and Chkraborty, D. (2008). Spatial Variability of Soil Properties and its Application in Predicting Surface Map of Hydraulic Parameters in an Agricultural Farm. Current Science, 95: 937-945.

Talkkari, A.; Lauri, J. and Markku Y. H. (2002). Geostatistical Prediction of Clay Percentage Based on Soil Survey Data Agricultural Journal, 11: 381- 390.

Tunçay, T; Bayramin, I; Atalay, F; and Unver, I. (2016). Assessment of Inverse Distance Weighting (IDW) Interpolation on Spatial 


\title{
Using The Inverted Distance Weighting Method (IDW) to Produce Maps of Some Soil Properties at the Agricultural Research Station, University of Tripoli
}

\author{
Magda Bashir El-beshti", Abuabdalla Saad Sherif and Ehab Mohamed Sagar \\ Department of Soil and Water, Faculty of Agriculture, University of Tripoli, Tripoli, Libya
}

Received: 04 May 2019/ Accepted: 30 December 2019

Doi: https://doi.org/10.54172/mjsc.v34i4.207

\begin{abstract}
The objective of the study was to determine the spatial differences of some physical and chemical properties of the soil samples of the research stations of the Faculty of Agriculture/University of Tripoli in April 2013. The results were used to produce spatial maps in order to find out the spacial distribution for the following properties: Bulk density (BD), Gravimetric water content (GWC), soil salinity (EC) and soil pH using the inverse distance weighting (IDW) method. The study was conducted on an area of approximately $13000 \mathrm{~m}^{2}$ and was divided into a $12 \mathrm{~m} \times 11$ $\mathrm{m}$ grid to produce 100 survey units and 36 units were chosen and coordinated by a portable GPS device to collect the samples. Tests were performed for both BD and GWC from depths $0-10 \mathrm{~cm}$, $10-20 \mathrm{~cm}$ and $20-30 \mathrm{~cm}$, while $\mathrm{EC}$ and $\mathrm{pH}$ analysis where done for samples from a depth of $30 \mathrm{~cm}$. Spatial maps were produced of continuous surfaces and quality that differed from one property to another according to the Root Mean Square Error (RMSE) values. Based on the results, the values of RMSE varied $(0.71,0.82$, and 0.86$)$ for the GWC and $(0.06,0.13,0.08)$ for the BD properties of the three depths, respectively. Where as the RMSE values were $(0.15,0.84)$ for the $\mathrm{pH}$ and EC properties respectively. The low RMSE values for BD maps at the first and third depths and the $\mathrm{pH}$ map showed a higher quality index for the maps. While the relatively high RMSE values showed that the maps produced for both EC and GWC properties were lower quality. This study concluded that it is possible to produce spatial maps of different quality for some soil properties within the field using IDW. These maps can therefore be used to predict $\mathrm{BD}$ and $\mathrm{pH}$ properties in the field, while they are difficult to predict for EC and GWC. Therefore, it is recommended to continue to explore the possibility of producing high-quality maps in other ways for these two properties, taking into account the increase in the number of the samples.
\end{abstract}

Keywords: Inverted Distance Weighting, Bulk Density, Volumetric Water Content, Soil Salinity, Soil pH. 